\section{A European Los Angeles?}

MONTPELlier has all the makings of Los Angeles, but it has a long way to go. For the time being, it differs by a fragment of a substantial mediaeval city wall, the like of which has never been seen in California, while it is still possible to look at clear blue sky. But not for long, if the fastest-growing city in France can keep up the momentum, it may soon have enough road vehicles to generate a pall of smog.

Montpellier also has the distinction of beginning as a university town. There are 200,000 permanent residents, but 50,000 university students who come and go.

Apart from the abundant youthfulness, the city has gone in for three contrasting and inconsistent architectural gimmicks whose like cannot easily be seen elsewhere. First, the old centre of the city has been covered with a sheet of terrazzo as vast as St Peter's Square, from whose edges protrude the upper floors of modern buildings, most of them apparently triangular, which are founded on solid earth. (The centrepiece of the display is a theatre, the Comédie, in which few plays play.)

Second, there is a gigantic air-conditioned bunker a good $300 \mathrm{~m}$ long in a distant corner, said to have cost more than $\$ 2,000$ million to build. It is a conference centre of the most modern kind, which provides the city with a car park and which is inhabited by the chamber of commerce and industry.

Third, there is the new home of the Conseil Général, the provincial government, constructed to a kind of athenian plan; there are half a dozen post-modern replicas of the portico of the Parthenon (with office suites behind) arranged in a semicircle and separated by a highway and an artificial river from the central office block, in glass and soft brown stone rising to a dozen stories. One Montpellier driver thinks the river a huge joke: "it would take a long time to get to the sea that way".

What is happening is that Montpellier believes it has a chance to become the most important city in the arc of the Mediterranean between Gibraltar and Marseilles. One picquant feature of the development is that the Socialist mayor of the city, Georges Frèche, and the Republican administration of the region, have sunk their political differences in this common cause.

Professor Roger Brunet, a geographer who is the director of the CNRS-financed "public interest group" RECLUS based at Montpellier, explains that there is a "launch-window" within which the city must somehow make its mark. ("RECLUS" stands for Réseau d'Etude des Changements dans lesLocalisations et des Unités Spatiales.)

The window opened in 1988, when the their cause. national government devolved to the departments certain responsibilities for education, planning and industrial development, and when Spain and Portugal joined the European Communities, enlarging the city's vision to the West. But growth had begun before that, in 1965, when IBM chose Montpellier for a manufacturing plant (now the chief source of employment after the three universities). Legend has it that somebody at IBM drew a line from the company's research laboratory at Nice to its import base at Bordeaux, and found Montpellier roughly half-way between.

With that beginning, Montpellier's ambition is to become a technopolis one blessed with sun and sea $(5 \mathrm{~km}$ to the south, past the airport and through a group of small factories). There are also the Cevennes mountains $10 \mathrm{~km}$ to the north. The other assets are the universities and the large group of research council laboratories (INRA is especially well established) scattered about the city. The city is also the main base of CIRAD, with responsibility for the cooperative development of tropical agriculture. The city and the region are setting out deliberately to exploit these assets, seeking to attract small and large enterprises in agriculture, pharmaceuticals and informatique to science parks physically designed to be contiguous with the laboratories in related fields.

Brunet, whose unit has general interests (it is using its expertise in cartography to compile an atlas of the world as well as of France, and has advanced the doctrine of territoriality as central to the present development of Europe) is a bystander, but an interested one. One of his projects is the conceptual design of a highway from Gibraltar to Constantinople, on which Montpellier would be a crucial stagingpost.

So when will the launch-window close? Montpellier seems realistically to appreciate that the world has become competitive. Toulouse, the centre of the aerospace and much of the electronics industry, is just $100 \mathrm{~km}$ to the northwest. More irritating, Nîmes, $50 \mathrm{~km}$ in the other direction, and best known for its splendid Roman ampitheatre, is nursing ambitions to expand (as, indeed, it is). The window will close only if the plans now hatched fail to materialize. Nobody in Montpellier believes that will happen.

\title{
Industrial mathematics booms
}

INDUSTRY seems to have taken to the heavy-duty computer and the techniques of model-building with the enthusiasm with which the French public has embraced Minitel - the ubiquitous domestic videotext service originally devised as an electronic telephone directory, but now used for gathering general information, train times for example. The result is that industrial researchers have set out deliberately to recruit mathematicians to

The impetus is twofold. Simulation is often much cheaper and quicker than experimental investigation, vividly apparent in the use of simulation by aeroengine manufacturers in the design of turbine blades (whence, in part, the present concentration of interest in fluid dynamics). The recognition of that truth is not unique to France. But what may be is the recognition by French industry that mathematics is one of the country's strongest suits, and that mathematicians are not always as unwilling to bother with practical problems as their reputation suggests.

But how to capture that resource? Elf's Solaize laboratory believes it has found an effective way of doing this, on behalf of the company's research effort as a whole. $\mathrm{J}-\mathrm{P}$. Valentin is a regular mathematician on the laboratory's full-time payroll who is not merely allowed, but required, to spend half his time on academic work.
For the rest, Valentin's job is a mix of persuading researchers in the company's laboratories that many of their problems are often essentially mathematical problems and then of recruiting appropriate outside consultants who can help to solve them. He says that he would be unable to perform the second role if he were not himself a practising mathematician, able to mix with others on equal terms at conferences.

$\mathrm{He}$ describes the first function as if it were a kind of psychoanalysis. Most researchers, unaware of recent advances in mathematics, are slow and even unwilling to acknowledge that their problems may be mathematical in character. People used to making measurements with an experimental rig prefer to stick with what they know. He also claims to be a kind of midwife, recognizing that one research group may already have a solution to another's problem.

Valentin cites as an important technique in his business the organization of regular meetings at which Elf-sponsored PhD students (there are 120 of them scattered about the universities) present accounts of their research in the presence of their academic supervisors. These serve, he says, not just as ways of recruiting consultants, but as a powerful means of deepen the company's corporate culture of mathematics. 